DOI: 10.20472/IAC.2018.935.036

\author{
VICTORIA NIKULINA \\ European University at Saint Petersburg, Russian Federation
}

MAXIM BOUEV

European University at Saint Petersburg, Russian Federation

\title{
MEASURING HERDING BEHAVIOR IN THE RUSSIAN STOCK MARKET
}

\begin{abstract}
:
This paper attempts to examine herding behavior in the Russian stock market by implementing four different methods designed to test for herding by Chang et al. (2000), Christie\&Huang (1995), Hwang\&Salmon (2001) and Torrecillas et al (2016). The main goal is to investigate the implications of the interest rate and foreign exchange fluctuations for the stock market efficiency. The results of the work help to identify the sources of herding behavior in the Russian stock market.

Employing different approaches towards measuring herding, it is possible to determine whether individuals copy each other's actions (Torrecillas et al (2016)) or herd towards market views about market index (Chang et al. (2000), Christie\&Huang (1995), Hwang\&Salmon (2001)).

This paper starts by the establishing the transition from efficient-market behavior to herding behavior by using Detrended Fluctuation Analysis (Torrecillas et al (2016)) applied to MICEX closing prices within the period from September 1997 to December 2017. The DFA reveals the presence of persistent herding behavior during the 2007-2009 crisis.

Next, Christie and Huang's CSSD measure of stock returns is used to capture if herding related to the firm-specific risk in the portfolio is present at the market. Consistent with results of the previous studies, the method fails to establish traces of herding. Christie and Huang's improved measure of CSSD with non-linear trend by Chang et al. (2000) yields evidence of herding in the down market during monetary policy announcements. The results of the Hwang and Salmon's state space models help to demonstrate herding related to the market risk by analyzing relative dispersion of the time-varying betas for assets. The main finding is that changes in the betas can't be explained by movements in fundamentals, which indicates intentional herding.

Therefore, bad news for the stock market (interest rate increase and currency depreciation) induce intentional herding in the Russian stock market. Intentional herding during market stress has important implications for portfolio diversification for both diversified and undiversified investors.
\end{abstract}

\section{Keywords:}

herd behavior, equity return dispersion, Russian stock market, state space models, market efficiency, detrended fluctuation analysis, financial crisis

JEL Classification: G14, C21, C58 